\title{
Heterogenous effects of sports participation on education and labor market outcomes
}

\section{Devon Gorry}

To cite this article: Devon Gorry (2016) Heterogenous effects of sports participation on education and labor market outcomes, Education Economics, 24:6, 622-638, DOI: 10.1080/09645292.2016.1143452

To link to this article: http://dx.doi.org/10.1080/09645292.2016.1143452

册Published online: 19 Feb 2016.

Submit your article to this journal $\pi$

III Article views: 172

Q View related articles $₫$

View Crossmark data \lceil

4 Citing articles: 1 View citing articles 진 


\section{Heterogenous effects of sports participation on education and labor market outcomes}

\section{Devon Gorry}

Department of Economics and Finance, Huntsman School of Business, Utah State University, Logan, UT, USA

\begin{abstract}
This paper analyzes the distribution of education and labor market benefits from sports participation. Results show that effects are similar across gender, but differ on other dimensions. In particular, participants in team sports show greater gains than those in individual sports. Quantile regressions show that educational gains are larger for low performing populations and earnings gains are larger for low earning individuals. Instrumental variable results also show similar effects across gender and larger gains in academic performance for low performers, but these results show insignificant effects of sports participation on labor market outcomes.
\end{abstract}

\section{ARTICLE HISTORY}

Received 22 August 2013

Accepted 8 January 2016

\section{KEYWORDS}

School sports; education; quantile regression

JEL

120; 124

\section{Introduction}

Schools provide one of the largest venues for youth athletic competition in the United States. According to the 2013-2014 High School Athletics Participation Survey, almost 7.8 million students participated in high school athletics (NFHS 2014). This accounts for almost half of the nation's more than 16 million high school students. Given that sports and schools are closely intertwined, it is important to understand how participation relates to the traditional educational objectives of schools. Education policy strives not just to improve performance, but also to reduce disparities in outcomes across individuals. To understand whether sports participation helps meet these goals we must know whether sports are associated with improved performance measures and which individuals are most affected by sports participation. Understanding the distribution of benefits will help policy makers decide whether sports reduce inequality or leave more children behind.

It is well established that sports participation is correlated with improved academic and labor market outcomes. ${ }^{1}$ This paper confirms these past findings with recent data from the National Longitudinal Study of Adolescent Health. Both regressions with and without controls reveal that middle and high school students who participate in sports earn higher grades, are more likely to graduate high school, are more likely to be employed, are less likely to be on welfare, and earn higher wages.

This paper extends the simple analyses and considers how gains from sports are distributed. Understanding how the relationship between sports participation and outcomes varies across sports and how gains are distributed across individuals can help policy makers decide whether providing school sports aligns with policy goals and think about which sports should be offered in schools. In addition, analyzing the distribution of benefits can help uncover potential mechanisms through which participation and outcomes are related. Finally, this paper carries out an instrumental variable analysis to test whether the gains from sport and distributional patterns in the data remain after accounting for endogenous selection into sports. 
While several theories may explain the association between athletic participation and improved outcomes, the association may also be driven by selection. If selection drives the results, playing sports may not cause better academic performances and higher wages. Instead, the type of people who are better in the classroom and more likely to succeed in the marketplace may also be more likely to participate in sports. While past evidence convincingly shows that athletes attain better outcomes, only a few studies provide evidence as to whether the relationship is causal or simply a selection effect. ${ }^{2}$ Even fewer studies analyze how the effects are distributed. ${ }^{3}$ Analyzing the distribution of effects not only has implications for how the benefits from sports participation may be distributed, but can also lends insights into causal channels.

Two main channels exist through which participation in sports can cause improved educational and marketplace outcomes. First, sports provide incentives for academic performance. School regulations requiring minimum standards be met for athletic participation provide one such incentive. In the US, a further incentive to stay in school is provided by the fact that venues to participate in athletics outside of school are limited. Thus, in order for individuals to stay on a team, they must keep their grades up and stay in school. This incentive effect implies that the students at the largest risk for earning poor grades or dropping out of school would benefit most from participating in sports.

A second possible causal channel is the development of human capital. Athletes learn valuable skills through athletic participation such as hard work, dedication, and cooperation that may help improve their classroom performance and future work capabilities. Early studies also suggest a socialization benefit of sports, where underachieving populations socialize with high performing peers. ${ }^{4}$ This channel may also lead to larger improvements in underachieving populations if they learn more from their peers. We would also expect different effects of participation across sports if there are different skills learned or varied degrees of socialization with one's teammates across sports.

To gain insight into the association between athletic participation and student outcomes, this paper analyzes whether heterogenous effects exist across sports and across participants. First, effects of participation are analyzed across the types of sports students play by breaking down participation into team and individual sports. Results show that participants in both team and individual sports achieve higher grades, but only participants in team sports show lasting gains with higher graduation rates and improved labor market outcomes. While these results could be consistent with differential selection across sports, they also suggest that there may be additional human capital gains or incentive effects associated with team sports.

Next, quantile regressions are estimated to understand the distribution of effects across individuals. Quantile regressions show that greater grade point average (GPA) gains are realized by low achieving students. Quantile regression is not used for high school graduation because it is a binary outcome, but separate regressions for students who have parents with low and high educational attainment show that students living with less educated parents realize greater gains in graduation rates. Thus, the greatest educational gains from sports participation appear to be concentrated in the low achieving populations. In addition, quantile regression shows that earnings gains are highest among low earning individuals. This distribution of effects implicates possible mechanisms. It is consistent with grade guidelines providing an incentive for students to improve their grades to be allowed to play sports. In this case we would expect greater gains at the bottom of the distribution where these guidelines are binding. The distribution of effects is also consistent with human capital gains from participating in sports with one's peers. In this situation we would expect that learning from more talented peers leads to greater gains for those at the bottom of the distribution. The fact that education and marketplace gains from sport are concentrated among the low achieving individuals does not rule out a selection effect, but it does lend support to the incentive and human capital theories. In addition, if effects are causal, these findings show that sports participation helps the individuals that need help most.

Finally, this paper implements an instrumental variables strategy to account for selection into sports participation. Although the distributional results align with theories of causal channels, endogenous selection into sports participation could also drive these results. For example, it could 
still be the case that sports attract harder working or more motivated individuals and that these traits lead to better outcomes for those at the bottom of the academic achievement or earnings distributions. It may also be the case that selection characteristics vary across the distribution of individuals. This paper uses school size and private school status to instrument for sports participation. The instrumental variable results continue to show a positive impact of sports participation on academic outcomes, but there are no longer significant effects on labor market outcomes after controlling for education. The distribution of effects remains similar for students' GPA gains, with low performing students realizing the highest gains. However, the effect on high school graduation is now strong for both students with low and high achieving parents. These results remain consistent with sports providing an incentive to perform better in school and building human capital. However, the insignificant effects on labor market outcomes suggests that there may not be lasting impacts of sports participation on labor market outcomes beyond increased educational attainment.

Section 2 gives an overview of the data, Section 3 presents the econometric methods used in this analysis, Section 4 presents the results, and Section 5 contains concluding remarks.

\section{Data}

This study analyzes data from the National Longitudinal Study of Adolescent Health (AddHealth) (Harris 2003; Harris et al. 2009). These data come from surveys conducted of students from a stratified random sample of 80 high schools and 52 middle schools across the country. Schools were chosen in an attempt to obtain a representative sample of US students with respect to region of country, urbanicity, school size, school type, and ethnicity. Since there is oversampling in some categories and attrition over time, sample weights are used to maintain a representative US sample.

AddHealth conducted four rounds of surveys. The first wave of the study targeted 7th through 12 th graders. This wave consisted of in-school and administrator questionnaires collected during the 1994-1995 school year. In addition, in-home surveys and parent questionnaires were obtained from April until December of 1995 during wave 1. The following year, wave 2 of the study conducted another round of in-home interviews and phone conversations with school administrators. The wave 3 follow up occurred from July 2001 through June 2002, 7 years after the initial surveys. This wave consisted of adult in-home interviews and permission was obtained to allow access to student's school records. Finally, wave 4 consisted of follow up in-home interviews conducted in 2008 and 2009. At the time of the latest interviews, participants were 24-34 years old. Although the data are collected as a panel, there are not multiple waves of sports data. The data structure for this analysis is effectively a cross-section since later waves are only used to gather outcome and control data.

The sports participation variables come from the wave 1 in-school student questionnaire. These data are unique because we know not just whether a student plays a sport, but which sport the student plays. Students were given a list of common sports 'found at many schools' as well as an 'other' category and asked to select 'any of them that you are participating in this year, or that you plan to participate in later in the school year.' If a student selected one or more choices from this list, they are counted as playing a sport. ${ }^{5}$ This same question is used to generate a team sport and an individual sport variable. Team sports were defined as sports where players must interact with multiple team members as part of the sport. Team sports include baseball, basketball, field hockey, football, ice hockey, soccer, and volleyball. Individual sports include sports that are largely determined by individual performance without the need to interact with teammates. Individual sports include tennis, track, swimming, and wrestling. ${ }^{6}$

Outcome data come from the first, third, and fourth survey waves. The wave 1 in-school questionnaire asked students to self report their most recent grade for English, History, Math, and Science. This reported GPA variable is an average of reported grades across subjects where A is coded as 4 , B is coded as 3, C is coded as 2, and 'D or below' is coded as $1 .^{7}$ While this variable has a large number of responses, it does not include all classes and is subject to reporting error. A more accurate and complete GPA variable comes from the transcript data obtained in round 3 of the survey. The 
GPA from the 94-95 school year transcript is used as this is the year when students reported whether or not they played sports.

Wave 3 and 4 responses generate the high school diploma variable. In wave 4 respondents are asked to report their high school graduation status. Those responding as having a diploma are coded as 1 while those who respond that they have a GED, a certificate of completion, or none of the above are coded as 0 . If wave 4 data is missing, wave 3 data is used. In wave 3 , respondents indicated whether they received a high school diploma. Those who indicate yes are coded as a 1 while those who did not indicate yes are coded as a zero.

The outcome data for working, welfare, and earnings variables come from wave 4 responses. Individuals are considered working if they indicated that they are currently working for pay at least 10 hours a week. Individuals are considered welfare users if they indicated that they or someone in their household received any public assistance, welfare, or food stamps in the time since their last survey. Finally, respondents were asked how much they received in personal earnings before taxes in the last year, and the log of this response is used for the earnings variable.

Control variables in this analysis include race, gender, parental education, school indicators, highest level of schooling, work experience, and region. Parental education is coded as the highest education of the most educated resident parent. The categories include completing high school, completing some college but no degree, obtaining a college degree, and education beyond college. Highest level of schooling is a categorical variable which represents the highest level of education reported in wave 4 . Work experience is calculated as the respondent's wave 4 age minus the age at which they began their first full time job.

Variables used to instrument for sports participation are school size and whether the school is private. School size is defined as the school roster size divided by the number of grades. Private school status is an indicator variable for whether a school is private.

Table 1 summarizes the data for the whole group as well as separately for athletes and non-athletes. It shows that approximately $55 \%$ of students in the study participate in sports, with $45 \%$ in team sports and $22 \%$ in individual sports. The average outcome variables suggests that athletes perform better than non-athletes in the classroom and in the marketplace. In the raw data, athletes average about 0.2 points higher on GPA, have a $6.7 \%$ higher graduation rate, are more likely to work, are less likely to use welfare, and earn almost $\$ 6500$ more a year than non-athletes on average.

Comparing the athlete to the non-athlete populations, participation is slightly skewed towards male participants: while over half the population is female, only $44 \%$ of the athletic participants are female. Table 1 also shows that athletes come from families with higher education on average. While this may confirm beliefs that sports attract higher ability students or benefit one gender more than another, this paper finds that athletes have improved outcomes even after controlling for background variables and these results are similar across gender. Finally, the instruments in Table 1 show that sport participants are more likely to come from smaller schools and private schools suggesting that these factors predict sports participation.

\section{Methods}

Analysis begins with regressions to estimate the basic relationship between athletic participation and outcomes. The outcomes include reported and transcript GPA, high school graduation, wave 4 employment, welfare use, and the log of earnings. The following specification is used:

$$
Y_{i s}=\alpha+\beta_{1} \text { sport }_{\text {is }}+\beta_{2} X_{i s}+\phi_{s}+\epsilon_{i s}
$$

Where $Y_{i s}$ represents an outcome variable for an individual, sport $_{i s}$ is an indicator for whether an individual plays a sport, $X_{i s}$ includes individual controls, and $\phi_{s}$ is a school fixed effect. For the high school graduation, employment, and welfare outcomes, a probit model is used. Due to the sampling of students within schools, standard errors robust to clustering within schools are used for these 
Table 1. Summary statistics.

\begin{tabular}{|c|c|c|c|c|c|c|c|c|c|}
\hline \multirow[b]{2}{*}{ Outcome variables } & \multicolumn{3}{|c|}{ All individuals } & \multicolumn{3}{|c|}{ Athletes } & \multicolumn{3}{|c|}{ Non-athletes } \\
\hline & Mean & Std. Dev. & $N^{\mathrm{a}}$ & Mean & Std. Dev. & $N$ & Mean & Std. Dev. & $N$ \\
\hline Transcript GPA & 2.649 & 0.871 & 6173 & 2.759 & 0.835 & 3275 & 2.519 & 0.894 & 2898 \\
\hline Reported GPA & 2.840 & 0.749 & 13374 & 2.919 & 0.727 & 7218 & 2.744 & 0.765 & 6156 \\
\hline HS diploma & 0.865 & 0.342 & 12112 & 0.895 & 0.307 & 6563 & 0.828 & 0.377 & 5549 \\
\hline Working & 0.788 & 0.409 & 8846 & 0.825 & 0.380 & 4729 & 0.744 & 0.436 & 4117 \\
\hline Welfare & 0.225 & 0.418 & 10716 & 0.188 & 0.391 & 5783 & 0.270 & 0.444 & 4933 \\
\hline Earnings & 38,327 & 44,409 & 9189 & 41,124 & 45,083 & 5098 & 34,636 & 43,229 & 4091 \\
\hline \multicolumn{10}{|l|}{ Sports participation } \\
\hline Sports participation & 0.550 & 0.497 & 13460 & 1 & 0 & 7251 & 0 & 0 & 6209 \\
\hline Team sport & 0.450 & 0.497 & 13460 & 0.817 & 0.386 & 7251 & 0 & 0 & 6209 \\
\hline Individual sport & 0.224 & 0.417 & 13460 & 0.407 & 0.491 & 7251 & 0 & 0 & 6209 \\
\hline Baseball & 0.19 & 0.392 & 13460 & 0.346 & 0.476 & 7251 & 0 & 0 & 6209 \\
\hline Basketball & 0.217 & 0.412 & 13460 & 0.394 & 0.489 & 7251 & 0 & 0 & 6209 \\
\hline Field hockey & 0.009 & 0.096 & 13460 & 0.017 & 0.129 & 7251 & 0 & 0 & 6209 \\
\hline Football & 0.134 & 0.341 & 13460 & 0.244 & 0.43 & 7251 & 0 & 0 & 6209 \\
\hline Ice hockey & 0.021 & 0.144 & 13460 & 0.038 & 0.192 & 7251 & 0 & 0 & 6209 \\
\hline Soccer & 0.08 & 0.272 & 13460 & 0.146 & 0.353 & 7251 & 0 & 0 & 6209 \\
\hline Swimming & 0.056 & 0.23 & 13460 & 0.102 & 0.303 & 7251 & 0 & 0 & 6209 \\
\hline Tennis & 0.042 & 0.202 & 13460 & 0.077 & 0.267 & 7251 & 0 & 0 & 6209 \\
\hline Track & 0.132 & 0.338 & 13460 & 0.239 & 0.427 & 7251 & 0 & 0 & 6209 \\
\hline Volleyball & 0.087 & 0.282 & 13460 & 0.159 & 0.366 & 7251 & 0 & 0 & 6209 \\
\hline Wrestling & 0.042 & 0.201 & 13460 & 0.077 & 0.267 & 7251 & 0 & 0 & 6209 \\
\hline Other sport & 0.091 & 0.287 & 13460 & 0.165 & 0.371 & 7251 & 0 & 0 & 6209 \\
\hline \multicolumn{10}{|l|}{ Control variables } \\
\hline Female & 0.504 & 0.500 & 13460 & 0.440 & 0.496 & 7251 & 0.583 & 0.493 & 6209 \\
\hline Grade & 9.369 & 1.699 & 13460 & 9.246 & 1.656 & 7251 & 9.520 & 1.738 & 6209 \\
\hline Black & 0.163 & 0.370 & 13460 & 0.154 & 0.361 & 7251 & 0.175 & 0.380 & 6209 \\
\hline Hispanic & 0.099 & 0.299 & 13460 & 0.080 & 0.271 & 7251 & 0.123 & 0.328 & 6209 \\
\hline Asian & 0.039 & 0.194 & 13460 & 0.036 & 0.186 & 7251 & 0.043 & 0.203 & 6209 \\
\hline Native American & 0.008 & 0.091 & 13460 & 0.007 & 0.083 & 7251 & 0.010 & 0.099 & 6209 \\
\hline Other & 0.046 & 0.210 & 13460 & 0.036 & 0.186 & 7251 & 0.059 & 0.235 & 6209 \\
\hline Parent HS & 0.275 & 0.447 & 13460 & 0.256 & 0.436 & 7251 & 0.299 & 0.458 & 6209 \\
\hline Parent some college & 0.223 & 0.416 & 13460 & 0.228 & 0.420 & 7251 & 0.217 & 0.412 & 6209 \\
\hline Parent college & 0.231 & 0.421 & 13460 & 0.254 & 0.435 & 7251 & 0.202 & 0.402 & 6209 \\
\hline Parent beyond college & 0.115 & 0.319 & 13460 & 0.139 & 0.346 & 7251 & 0.085 & 0.279 & 6209 \\
\hline Highest schooling ${ }^{b}$ & 5.737 & 1.920 & 9189 & 5.958 & 1.850 & 5098 & 5.446 & 1.972 & 4091 \\
\hline Worklife & 8.929 & 3.159 & 9189 & 8.608 & 3.156 & 5098 & 9.352 & 3.113 & 4091 \\
\hline \multicolumn{10}{|l|}{ Instrumental variables } \\
\hline School size & 312 & 228 & 13188 & 274 & 211 & 7127 & 356 & 238 & 6061 \\
\hline Private & 0.080 & 0.271 & 13459 & 0.116 & 0.321 & 7251 & 0.037 & 0.189 & 6208 \\
\hline
\end{tabular}

Note: AddHealth sample weights are used.

${ }^{a}$ Different sample sizes are due to missing data in the outcome variables.

${ }^{\mathrm{b}}$ Highest schooling is a categorical variable ranging from 1 to 13 .

regressions. In addition, sampling weights provided in the AddHealth data are used. ${ }^{8}$ These regressions are similar to past studies which look at the association between sports participation and outcomes.

This paper extends the analysis by looking at effects across gender, across type of sport, and by using quantile regression to look at how the effects are distributed across the conditional distribution of outcome variables. All results are shown with the full data set and then separately by gender to look for gender differences. To examine how the effects of sports participation vary depending on whether an individual participates in a team or individual sport, the following specification is used:

$$
Y_{\text {is }}=\alpha+\beta_{1} \text { teamsport }_{\text {is }}+\beta_{2} \text { indsport }_{\text {is }}+\beta_{3} X_{i s}+\phi_{s}+\epsilon_{\text {is }} .
$$

To explore the distribution of the association between sports participation and outcomes, first, the effect of participation on GPA is analyzed across the conditional GPA distribution using quantile regression. Because sports participation may influence the conditional distribution of the response 
differently along the distribution, quantile regression is the appropriate method to analyze the effect of athletic participation on GPA. The following equation is used,

$$
Y_{i}=\alpha+\beta_{1} \text { sport }_{i}+\beta_{2} X_{i}+\epsilon_{i}
$$

In quantile regression, instead of minimizing the squared residuals to find how the conditional mean of the outcome parameters change with changes in covariates, the sum of asymmetrically weighted absolute residuals is minimized to obtain the conditional quantile function (Koenker and Hallock 2001). Bootstrapped standard errors are calculated.

The effect of sports participation on wages is also analyzed across the conditional wage distribution using quantile regression as above. This technique allows us to see the correlation between sports participation and earnings at different points along the conditional earnings distribution to see if gains are associated more with high or low earners. Quantile regression provides a more complete picture of the distribution of effects of sports participation on outcomes.

The association between athletic participation and high school graduation cannot be broken out by quantiles since the outcome variable is binary. Instead, the effect of sports participation on high school graduation is broken down by subgroups of the population based on parental education. Typically, children who have parents with low education are less likely to graduate than those who come from highly educated families. Thus, the high school graduation regressions are run separately for individuals that come from high educated households and low educated households. If an individual lives with at least one parent that has some college education or above, they are considered to come from a high educated household. Otherwise they are assigned to the low educated household group. Specification (1) from above is run for each subgroup.

While the distribution of benefits from sports is illuminating, we do not know whether there are different causal effects across subgroups or if there is differential selection across subgroups. In order to examine this question, this paper uses an instrumental variables strategy to investigate the average as well as quantile effects of sports participation. This paper follows a similar strategy to Barron, Ewing, and Waddell (2000) and Pfeifer and Cornelissen (2001) by instrumenting for sports participation with school size and private school status. ${ }^{9}$

School size provides a useful instrument because schools have a limited number of sports teams and roster space. Thus, it will be harder for students to make the team if they come from a bigger school. While experimental designs in the literature have shown that class size can impact student achievement in the early grades (Angrist and Lavy 1999; Krueger and Whitmore 2001), there has not been convincing evidence to show that school size directly impacts performance. ${ }^{10}$ Recent studies on programs to convert large schools into smaller schools find little evidence of direct effects on student achievement, suggesting that school size is a valid instrument. $^{11}$

Private school status is used as an instrument because private schools tend to have more sports teams and some of these schools require sports participation, thus making participation more likely. Moreover, voucher studies in the U.S. use experimental data to examine the effect of receiving a voucher for a private school, and these studies find relatively small or no achievement effects of attending a private school (Rouse and Barrow 2009) suggesting that private schools do not impact educational outcomes directly.

Instrumental variable analysis is first run for the basic specification. A probit model is estimated in the first stage and the predicted values are used as instruments in the second stage. To explore the distribution of effects, this paper also utilizes instruments for the quantile regressions following Chernozhukov, Fernandez-Val, and Kowalski (2014). In addition, separate high school graduation regressions are run by parental education. 


\section{Results}

\subsection{Basic findings}

The regression results confirm previous findings which show a positive relationship between athletic participation and outcomes. Table 2 presents regressions comparable with those from previous literature and also shows the results separated by gender. The $a$ columns for each outcome present the simple regressions without controls. Participating in sports is associated with improved outcomes in every category and the results are similar if we look at males and females together or analyze them separately.

The $b$ columns in Table 2 include controls and school fixed effects. School fixed effects control for unobserved factors that are fixed within schools. Even after adding controls, sports participation is correlated with significant gains. The $b$ columns show that athletic participation is associated with a 0.215 point higher transcript GPA, a 0.153 higher reported GPA, a 5.2 percentage point increase in the probability of graduating high school, a 3.8 percentage point increase in the probability of being employed at the last survey, a 4.0 percentage point decrease in the probability of using welfare, and a $9.6 \%$ increase in earnings. Again, these effects do not substantially differ by gender and all the effects are significant at the $10 \%$ level or lower.

Thus, using AddHealth data, results are similar to past research which shows significant educational and labor market gains associated with sports participation. Moreover, both males and females show substantial gains. Overall, the results are similar across gender. The largest difference across gender is the effect of participation on high school graduation where the magnitude for males is almost twice that for females.

\subsection{Team and individual sports}

In order to better understand the positive associations with sports participation, this paper analyzes the effects of different types of sports. Examining team and individual sports participation separately can lend greater insight into which sports may benefit participants and the mechanisms that generate the relationships in Table 2. If selection is responsible for the disparity in outcomes between athletes and non-athletes, one would expect that high performing students select into both types of sports leading to similar outcomes for team and individual athletes. However, if incentive mechanisms or human capital development are responsible for improved performances of athletes, then differences in outcomes across team and individual sports may arise.

Sports can incentivize schooling performance or attendance through multiple avenues. Many schools set participation requirements which set minimum grade standards for participation in sports. This type of incentive may provide uniform results across team and individual athletes. However, athletes playing team sports may have more pressure from their peers to meet the minimum standards as no team likes losing strong players. There is also an incentive effect to stay in school in order to continue participating in sports. This incentive is likely to be stronger for team sports because it is more difficult to find a venue for team sports outside of schools and peer pressure from teammates to stay in school is again likely to be stronger.

If a human capital mechanism generates the observed patterns in the data, we would also expect differences across the type of sport. Team sports require students to work with others, follow rules, and cooperate with teammates while individual sports largely focus upon one's personal performance. Given that different sports teach different skills, we would not expect participation to lead to uniform payoffs across sports in school or workforce performance.

Table 3 presents a breakdown of athletic participation into team and individual sports. Except for GPA, there are large disparities in the effects of team and individual athletic participation. Focussing on the $b$ columns which include controls, Table 3 shows that the effect of sports participation on GPA is similar for team and individual sports. This is true for both males and females. However, large 
Table 2. Sports participation and academic and labor market outcomes.

\begin{tabular}{|c|c|c|c|c|c|c|c|c|c|c|c|c|}
\hline & \multicolumn{2}{|c|}{ Transcript GPA } & \multicolumn{2}{|c|}{ Reported GPA } & \multicolumn{2}{|c|}{ HS diploma ${ }^{a}$} & \multicolumn{2}{|c|}{ Employed $^{a}$} & \multicolumn{2}{|c|}{ Welfare $^{a}$} & \multicolumn{2}{|c|}{ Log earnings } \\
\hline & $\bar{a}$ & $b$ & $\bar{a}$ & $b$ & $\bar{a}$ & $b$ & $\bar{a}$ & $b$ & $\bar{a}$ & $b$ & $\bar{a}$ & $b$ \\
\hline & \multicolumn{12}{|c|}{ Males and females } \\
\hline \multirow[t]{2}{*}{ Sports prticipation } & $0.239^{* *}$ & $0.215^{* *}$ & $0.175^{* *}$ & $0.153^{* *}$ & $0.065^{* *}$ & $0.052^{* *}$ & $0.079^{* *}$ & $0.038^{* *}$ & $-0.082^{* *}$ & $-0.040^{* *}$ & $0.202^{* *}$ & $0.092^{* *}$ \\
\hline & $(0.040)$ & $(0.035)$ & $(0.019)$ & $(0.017)$ & $(0.011)$ & $(0.008)$ & $(0.015)$ & $(0.013)$ & $(0.011)$ & $(0.010)$ & $(0.026)$ & $(0.026)$ \\
\hline \multirow[t]{2}{*}{ Observations } & 6173 & 6173 & 13374 & 13374 & 11765 & 11765 & 8829 & 8829 & 10696 & 10696 & 9189 & 9189 \\
\hline & \multicolumn{12}{|c|}{ Males } \\
\hline \multirow[t]{2}{*}{ Sports participation } & $0.300^{* *}$ & $0.218^{* *}$ & $0.219^{* *}$ & $0.157^{* *}$ & $0.088^{* *}$ & $0.069^{* *}$ & $0.042^{*}$ & $0.034^{+}$ & $-0.054^{* *}$ & $-0.031^{*}$ & $0.109^{* *}$ & $0.072^{+}$ \\
\hline & $(0.058)$ & $(0.054)$ & $(0.029)$ & $(0.027)$ & $(0.018)$ & $(0.014)$ & $(0.019)$ & $(0.018)$ & $(0.016)$ & $(0.015)$ & $(0.040)$ & $(0.041)$ \\
\hline \multirow[t]{2}{*}{ Observations } & 2919 & 2919 & 6433 & 6433 & 5470 & 5470 & 3905 & 3905 & 4886 & 4886 & 4415 & 4415 \\
\hline & \multicolumn{12}{|c|}{ Females } \\
\hline \multirow[t]{2}{*}{ Sports participation } & $0.302^{* *}$ & $0.218^{* *}$ & $0.196^{* *}$ & $0.148^{* *}$ & $0.057^{* *}$ & $0.037^{* *}$ & $0.084^{* *}$ & $0.043^{*}$ & $-0.081^{* *}$ & $-0.044^{* *}$ & $0.200^{* *}$ & $0.101^{*}$ \\
\hline & $(0.049)$ & $(0.045)$ & $(0.023)$ & $(0.022)$ & $(0.013)$ & $(0.010)$ & $(0.021)$ & $(0.019)$ & $(0.017)$ & $(0.015)$ & $(0.040)$ & $(0.042)$ \\
\hline Observations & 3254 & 3254 & 6941 & 6941 & 5963 & 5963 & 4831 & 4831 & 5770 & 5770 & 4774 & 4774 \\
\hline
\end{tabular}

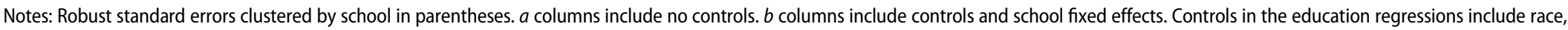

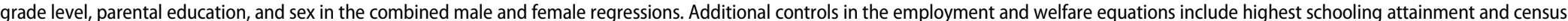
region for wave 4 . Further additional controls in the earnings equation include work experience and work experience squared. AddHealth sample weights are used in all specifications.

${ }^{a}$ Coefficients from probit model represent the marginal effects at the mean.

${ }^{+} p<0.1$.

${ }^{*} p<0.05$.

${ }^{* *} p<0.01$. 
Table 3. Sports participation and academic and labor market outcomes: team and individual sports.

\begin{tabular}{|c|c|c|c|c|c|c|c|c|c|c|c|c|}
\hline & \multicolumn{2}{|c|}{ Transcript GPA } & \multicolumn{2}{|c|}{ Reported GPA } & \multicolumn{2}{|c|}{$\mathrm{HS}_{\text {diploma }}{ }^{\mathrm{a}}$} & \multicolumn{2}{|c|}{ Employed $^{\text {a }}$} & \multicolumn{2}{|c|}{ Welfare $^{\mathrm{a}}$} & \multicolumn{2}{|c|}{ Log earnings } \\
\hline & $a$ & $b$ & $a$ & $b$ & $a$ & $b$ & $a$ & $b$ & $a$ & $b$ & $a$ & $b$ \\
\hline & \multicolumn{12}{|c|}{ Males and females } \\
\hline Team sport & $0.080^{*}$ & $0.106^{* *}$ & $0.096^{* *}$ & $0.106^{* *}$ & $0.043^{* *}$ & $0.049^{* *}$ & $0.073^{* *}$ & $0.047^{* *}$ & $-0.061^{* *}$ & $-0.039^{* *}$ & $0.142^{* *}$ & $0.083^{* *}$ \\
\hline Ind sport & $\begin{array}{l}(0.03 /) \\
0.211^{* *}\end{array}$ & $\begin{array}{l}(0.031) \\
0.129^{* *}\end{array}$ & $\begin{array}{l}(0.019) \\
0.138^{* *}\end{array}$ & $\begin{array}{l}(0.016) \\
0.088^{* *}\end{array}$ & $\begin{array}{c}(0.009) \\
0.024^{+}\end{array}$ & $\begin{array}{c}(0.007) \\
0.005\end{array}$ & $\begin{array}{c}(0.014) \\
-0.013\end{array}$ & $\begin{array}{l}(0.014) \\
-0.030\end{array}$ & $\begin{array}{c}(0.012) \\
-0.030^{*}\end{array}$ & $\begin{array}{c}(0.011) \\
-0.006\end{array}$ & $\begin{array}{c}(0.027) \\
0.087^{*}\end{array}$ & $\begin{array}{c}(0.029) \\
0.025\end{array}$ \\
\hline & $(0.044)$ & $(0.035)$ & $(0.023)$ & $(0.020)$ & $(0.013)$ & $(0.011)$ & $(0.018)$ & $(0.019)$ & $(0.014)$ & $(0.013)$ & $(0.034)$ & $(0.031)$ \\
\hline$F$-stat ${ }^{\mathrm{b}}$ & $4.150^{*}$ & 0.245 & 1.663 & 0.464 & 0.913 & $7.116^{* *}$ & $15.690^{* *}$ & $8.989^{* *}$ & 2.058 & $2.986^{+}$ & 1.305 & 1.668 \\
\hline Observations & \multicolumn{12}{|c|}{ Males } \\
\hline Team sport & $\begin{array}{c}0.125^{*} \\
(0.048)\end{array}$ & $\begin{array}{c}0.107^{*} \\
(0.043)\end{array}$ & $\begin{array}{l}0.125^{* *} \\
(0.027)\end{array}$ & $\begin{array}{l}0.101^{* *} \\
(0.025)\end{array}$ & $\begin{array}{l}0.060^{* *} \\
(0.017)\end{array}$ & $\begin{array}{l}0.060^{* *} \\
(0.015)\end{array}$ & $\begin{array}{l}0.046^{* *} \\
(0.018)\end{array}$ & $\begin{array}{l}0.056^{* *} \\
(0.016)\end{array}$ & $\begin{array}{c}-0.047^{* *} \\
(0.015)\end{array}$ & $\begin{array}{c}-0.045^{* *} \\
(0.015)\end{array}$ & $\begin{array}{c}0.064 \\
(0.040)\end{array}$ & $\begin{array}{c}0.089^{*} \\
(0.040)\end{array}$ \\
\hline Ind sport & $\begin{array}{l}0.260^{* *} \\
(0.061)\end{array}$ & $\begin{array}{c}0.131^{*} \\
(0.050)\end{array}$ & $\begin{array}{l}0.153^{* *} \\
(0.028)\end{array}$ & $\begin{array}{l}0.092^{* *} \\
(0.029)\end{array}$ & $\begin{array}{c}0.026 \\
(0.021)\end{array}$ & $\begin{array}{c}0.006 \\
(0.018)\end{array}$ & $\begin{array}{c}-0.026 \\
(0.027)\end{array}$ & $\begin{array}{c}-0.043^{+} \\
(0.024)\end{array}$ & $\begin{array}{c}-0.012 \\
(0.021)\end{array}$ & $\begin{array}{c}0.017 \\
(0.020)\end{array}$ & $\begin{array}{c}0.090^{*} \\
(0.042)\end{array}$ & $\begin{array}{c}0.025 \\
(0.039)\end{array}$ \\
\hline$F$-stat ${ }^{\mathrm{b}}$ & 2.754 & 0.167 & 0.481 & 0.042 & 1.111 & $3.565^{+}$ & $5.161^{*}$ & $10.863^{* *}$ & 1.446 & $5.273^{*}$ & 0.161 & 1.084 \\
\hline Observations & 2919 & 2919 & 6433 & 6433 & 5470 & 5470 & $\begin{array}{l}3905 \\
\text { hales }\end{array}$ & 3905 & 4886 & 4886 & 4415 & 4415 \\
\hline Team sport & $\begin{array}{l}0.167^{* *} \\
(0.050)\end{array}$ & $\begin{array}{c}0.115^{*} \\
(0.045)\end{array}$ & $\begin{array}{l}0.142^{* *} \\
(0.025)\end{array}$ & $\begin{array}{l}0.112^{* *} \\
(0.024)\end{array}$ & $\begin{array}{l}0.041^{* *} \\
(0.012)\end{array}$ & $\begin{array}{l}0.039^{* *} \\
(0.010)\end{array}$ & $\begin{array}{l}0.063^{* *} \\
(0.021)\end{array}$ & $\begin{array}{c}0.043^{+} \\
(0.023)\end{array}$ & $\begin{array}{r}-0.041^{*} \\
(0.018)\end{array}$ & $\begin{array}{c}-0.019 \\
(0.017)\end{array}$ & $\begin{array}{c}0.100^{*} \\
(0.044)\end{array}$ & $\begin{array}{c}0.084^{+} \\
(0.045)\end{array}$ \\
\hline Ind sport & $\begin{array}{l}0.173^{* *} \\
(0.050)\end{array}$ & $\begin{array}{l}0.116^{* *} \\
(0.039)\end{array}$ & $\begin{array}{l}0.116^{* *} \\
(0.033)\end{array}$ & $\begin{array}{c}0.069^{*} \\
(0.027)\end{array}$ & $\begin{array}{c}0.019 \\
(0.014)\end{array}$ & $\begin{array}{c}0.004 \\
(0.012)\end{array}$ & $\begin{array}{c}0.004 \\
(0.023)\end{array}$ & $\begin{array}{c}-0.015 \\
(0.024)\end{array}$ & $\begin{array}{r}-0.053^{*} \\
(0.022)\end{array}$ & $\begin{array}{c}-0.042^{*} \\
(0.019)\end{array}$ & $\begin{array}{c}0.099^{+} \\
(0.051)\end{array}$ & $\begin{array}{c}0.018 \\
(0.047)\end{array}$ \\
\hline$F$-stat ${ }^{b}$ & 0.007 & 0.000 & 0.335 & 1.259 & 1.168 & $4.149^{*}$ & $3.628^{+}$ & 2.629 & 0.127 & 0.626 & 0.000 & 0.974 \\
\hline Observations & 3254 & 3254 & 6941 & 6941 & 5963 & 5963 & 4831 & 4831 & 5770 & 5770 & 4774 & 4774 \\
\hline
\end{tabular}

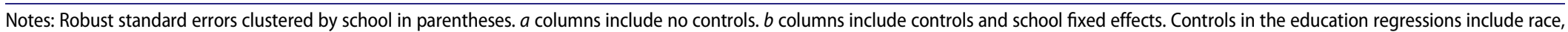

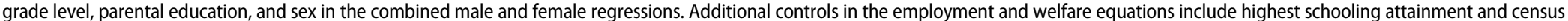
region for wave 4 . Further controls in the earnings equation include work experience and experience squared. AddHealth sample weights are used.

${ }^{a}$ Coefficients from probit model represent the marginal effects at the mean.

${ }^{\mathrm{b}} F$ statistic for a test of whether the team sport and individual sport coefficients are equal.

$+p<0.1$.

${ }^{*} p<0.05$.

${ }^{* *} p<0.01$. 
differences exist between team and individual sports participation for high school graduation. Team sports participation is associated with a 4.9 percentage point increase in high school graduation but individual sports participation is only associated with a 0.5 percentage point increase in high school graduation, with a significant difference between the coefficients at the $5 \%$ level. When graduation results are broken down by gender, both males and females benefit from team sports participation, but the benefit of individual sports participation is smaller and insignificant. Thus, while both team and individual sports are associated with higher grades, only team sports are associated with increases in high school graduation.

The disparity between team and individual sports continues for labor market outcomes. Overall, the regressions with controls show that team sports participation is associated with a 4.7 percentage point increase in employment, a 3.9 percentage point decrease in welfare use and an $8.7 \%$ increase in earnings. However, individual sports participation is not associated with significant improvements in labor market outcomes. The patten is similar across gender. The main difference is that women who play individual sports show larger reductions in welfare use. However, for the employment and earnings outcomes, males and females only see significant gains associated with team sports.

The fact that there are large differences in the effects of team and individual sports can be explained by different selection into sports. This would result if high performing individuals are more likely to select into team sports but selection into individual sports does not differ by ability. In this case, team sport participation could signal desirable worker characteristics to employers. It is also possible that there are different incentive or human capital effects from participating in sports that vary by type of sport. If this is the case, it is team sports that provide larger educational and labor market gains.

\subsection{Distribution of benefits}

While it is valuable to understand which types of sports are associated with the largest gains, it is also important to understand how the gains are distributed across individuals. The distribution of benefits must be taken into account when assessing if sports should be implemented within schools and can provide insight about the mechanisms through which athletes attain better outcomes. The results of the distributional analyses show that the biggest gains from sports are concentrated in low achieving populations.

Table 4 uses quantile regression to evaluate the distribution of GPA gains associated with sports participation. Transcript GPA is used because it better represents a student's overall performance and is more accurately reported. By using quantile regression, we estimate the marginal effect of athletic

Table 4. Effect of sports participation on GPA by quantile.

\begin{tabular}{|c|c|c|c|c|c|}
\hline & 0.1 & 0.25 & 0.5 & 0.75 & 0.9 \\
\hline & \multicolumn{5}{|c|}{ Males and females } \\
\hline \multirow[t]{2}{*}{ Sports participation } & $0.340^{* *}$ & $0.305^{* *}$ & $0.235^{* *}$ & $0.163^{* *}$ & $0.080^{* *}$ \\
\hline & $(0.043)$ & $(0.035)$ & $(0.027)$ & $(0.026)$ & $(0.025)$ \\
\hline \multirow[t]{2}{*}{ Observations } & 6316 & 6316 & 6316 & 6316 & 6316 \\
\hline & & & Males & & \\
\hline \multirow[t]{2}{*}{ Sports participation } & $0.403^{* *}$ & $0.327^{* *}$ & $0.270^{* *}$ & $0.170^{* *}$ & $0.150^{* *}$ \\
\hline & $(0.068)$ & $(0.048)$ & $(0.041)$ & $(0.041)$ & $(0.048)$ \\
\hline \multirow[t]{2}{*}{ Observations } & 2989 & 2989 & 2989 & 2989 & 2989 \\
\hline & & & Females & & \\
\hline \multirow[t]{2}{*}{ Sports participation } & $0.324^{* *}$ & $0.280^{* *}$ & $0.215^{* *}$ & $0.152^{* *}$ & $0.050^{+}$ \\
\hline & $(0.060)$ & $(0.045)$ & $(0.036)$ & $(0.035)$ & $(0.029)$ \\
\hline Observations & 3327 & 3327 & 3327 & 3327 & 3327 \\
\hline \multicolumn{6}{|c|}{$\begin{array}{l}\text { Notes: Bootstrapped standard errors in parentheses. Controls include race, grade level, parental education, and sex in the combined } \\
\text { male and female regressions. }\end{array}$} \\
\hline
\end{tabular}


participation on GPA for students at different points in the conditional GPA distribution instead of estimating only the mean effect.

Sports participation in schools is often dependent upon meeting a minimum GPA standard. If this standard encourages better performance, there would be larger effects at the bottom of the GPA distribution where the standards are binding. If human capital development occurs through learning from one's peers, the bottom of the distribution may also see the largest gains by learning from their high achieving peers. Table 4 shows that the largest associations between sports participation and GPA do, in fact, occur at the bottom of the achievement spectrum. At the 0.1 quantile, participation in sports is associated with a 0.34 point increase in transcript GPA. At the 0.25 quantile, this reduces to a 0.305 point increase, and by the 0.9 quantile athletic participation is only associated with a 0.08 point increase. When broken out by gender, low performers still exhibit the largest gains associated with sports participation. While these results are consistent with both the incentive and human capital theories, they do not rule out differential selection into sports across quantiles. However, if these results are causal then sports provide an avenue to reduce the gaps in educational achievement.

Table 5 presents the associations between athletic participation and high school graduation broken down by parental education. Typically, children of more educated parents attain more education themselves. Thus, by breaking up the groups, we can see whether sports participation has larger effects on those from low educated households who are less likely to graduate or those from high educated households who are already more likely to graduate given their family background. Table 5 shows that sports participation is correlated with larger gains in high school graduation for individuals from low educated families. These athletes have an 8.1 percentage point increase in graduation rates. The relationship is much smaller for individuals from high educated families where sports participants only see a 3.3 percentage point increase in graduation rates. This pattern is consistent for males and females. Although males see larger gains in these specifications, the largest gains are associated with those from low educated households for both males and females. These results show that gains from sport are concentrated in the low achieving populations, and if this is driven by causal effects then sports are helping those most at risk of not graduating.

Quantile regressions are used again to analyze the distribution of effects of sports participation on earnings. Table 6 shows that all individuals who play sports exhibit higher wages, but the greatest wage increases are among low earners. While sports participants have $17.2 \%$ higher earnings at the 0.1 quantile, participants at the 0.9 quantile of earnings only have a $4.9 \%$ increase in earnings. When the results are broken out by gender, differences develop. While males show a trend similar to the combined effects, females have a relatively constant coefficient across quantiles except at

Table 5. Effect of sports participation on H.S. graduation by parental education.

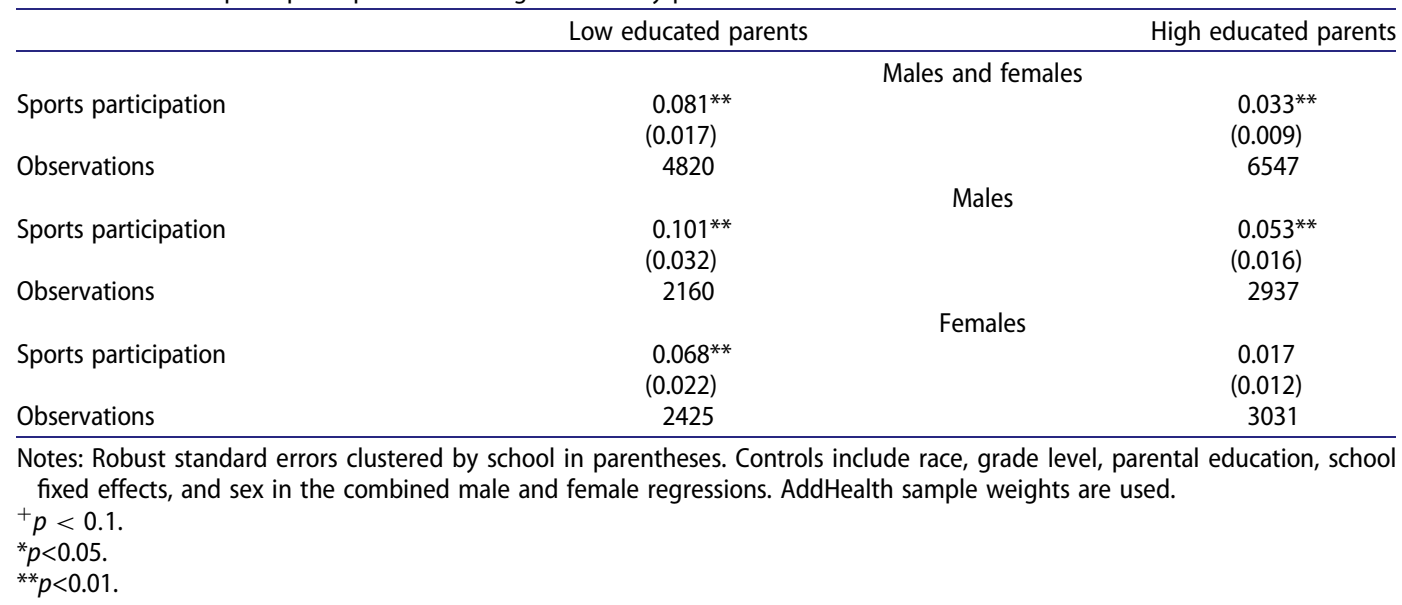


Table 6. Effect of sports participation on earnings by quantile.

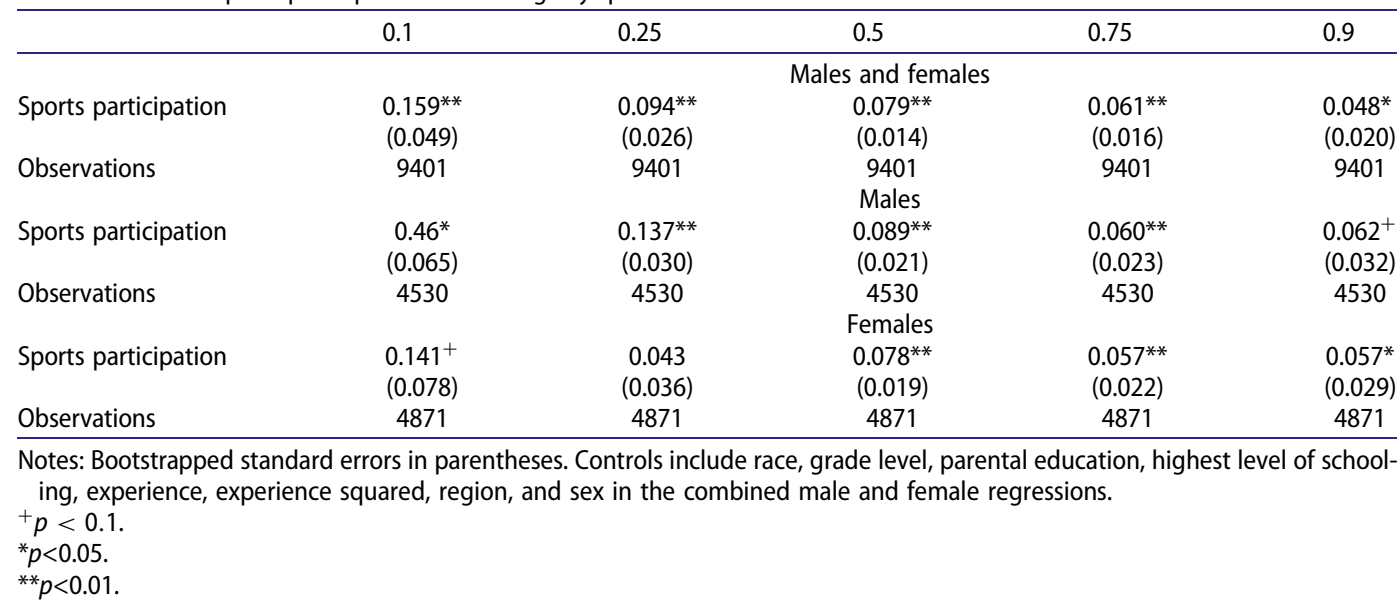

the very bottom of the distribution where there is a larger association between wages and sports participation. Among males, low earners see higher gains associated with sports, but among females the differences in the gains from sports across the distribution of earnings is not as strong. If these results are causal, then sports provide an avenue to reduce income inequality, particularly among men.

\subsection{Instrumental variable analysis}

While distributional results suggest causal channels for sports participation to improve academic performance, selection could still be driving these results. This would occur if there is differential selection across quantiles or if endogenous characteristics that influence sports participation have differential effects across quantiles. An instrumental variables strategy is employed to overcome such selection effects and explore whether effects of sports participation remain. Valid instruments for this strategy must be strongly related to participation in sports and unrelated to the outcome measures except through the sports participation channel. This paper follows previous strategies in the literature for instruments (see Barron, Ewing, and Waddell 2000; Pfeifer and Cornelissen 2001), but extends previous instrumental variables results by looking at the distributional results through quantile estimation. The instrumental variables results confirm educational gains concentrated in the low performing populations, but show no gains in labor market outcomes. Conditional on having valid instruments, these results show that there are educational gains realized by participation and low performing populations benefit most.

Table 7 provides the first stage results for the excluded instruments in the instrumental variable regressions. There is a separate first stage regression for each outcome variable as the samples vary across outcomes. These results show that the instruments are good predictors of sports participation. As theory suggests, sports participation is associated with smaller school sizes and attending a private school. The $F$-statistics for the excluded instruments are greater than 10 in all cases and also exceed the Stock-Yogo critical values, which suggests that the instruments explain significant variation in sports participation and there will not be biased or inconsistent results due to weak instruments (Bound, Jaeger, and Baker 1995; Staiger and Stock 1997; Stock and Yogo 2005).

Table 8 provides the instrumental variables estimates that align with the basic regressions in Table $2 .{ }^{12}$ While the estimates are imprecise due to large standard errors associated with instrumental variables regressions, the direction of the results for educational outcomes tell a similar story to the earlier results. Sports participation is associated with higher grades and an increased graduation rate. Results for transcript grades, reported grades, and high school graduation show significant gains from sports participation overall and for males and females separately. These results are the same 
Table 7. First stage regressions.

\begin{tabular}{lcccccc}
\hline \multirow{2}{*}{ Sample: } & Outcome: sports participation & & & \\
\cline { 2 - 6 } & Transcript GPA & Reported GPA & HS diploma & Employed & Welfare & Log earnings \\
\hline School size & $-0.024^{* *}$ & $-0.025^{* *}$ & $-0.027^{* *}$ & $-0.029^{* *}$ & $-0.028^{* *}$ & $-0.028^{* *}$ \\
& $(0.007)$ & $(0.005)$ & $(0.006)$ & $(0.005)$ & $(0.005)$ & $(0.005)$ \\
Private & $0.201^{* *}$ & $0.189^{* *}$ & $0.185^{* *}$ & $0.172^{* *}$ & $0.166^{* *}$ & $0.173^{* *}$ \\
& $(0.040)$ & $(0.047)$ & $(0.045)$ & $(0.049)$ & $(0.049)$ & $(0.047)$ \\
Observations & 6217 & 13,947 & 12,122 & 8877 & 10,738 & 9215 \\
F-stat on excluded instruments & 32.91 & 30.26 & 33.76 & 35.75 & 33.79 & 36.36 \\
\hline
\end{tabular}

Notes: Robust standard errors clustered by school in parentheses. Regression results from separate first stage regressions for each outcome variable. Coefficients from probit model represent the marginal effects at the mean. Controls in the education regressions include race, grade level, parental education, and sex in the combined male and female regressions. Additional controls in the employment and welfare equations include highest schooling attainment and census region for wave 4 . Further additional controls in the earnings equation include work experience and work experience squared.

$+p<0.1$.

${ }^{*} p<0.05$.

${ }^{* *} p<0.01$.

direction as the OLS results in Table 2. However, the labor market outcomes are no longer significant which could indicate that there are no additional benefits in the labor market beyond increased educational performance.

Table 9 uses instrumental variables for the quantile estimation to look at the distribution of effects of sports participation on GPA. Similar to the quantile results in Table 4, this table shows that the positive effects of sports on GPA are largest in the bottom quantiles. For both males and females, the bottom quantiles experience the greatest improvements in GPA. This aligns with the initial GPA quantile results, suggesting that the low performers benefit most.

Table 10 uses instrumental variables estimation to estimate the effect of sports participation on high school graduation by parental education. While the basic OLS results suggest that the athletes from low educated households experienced greater gains than those from high educated households, the instrumental variable results in Table 10 show that athletes from both high and low educated households see similar improvements in high school graduation rates, with slightly higher coefficients for students from high educated households.

Finally, Table 11 provides the instrumental variables quantile estimation of sports participation on wages. Here, the instrumental variables results show a different picture than the quantile results in

Table 8. IV regression of sports participation on academic and labor market outcomes.

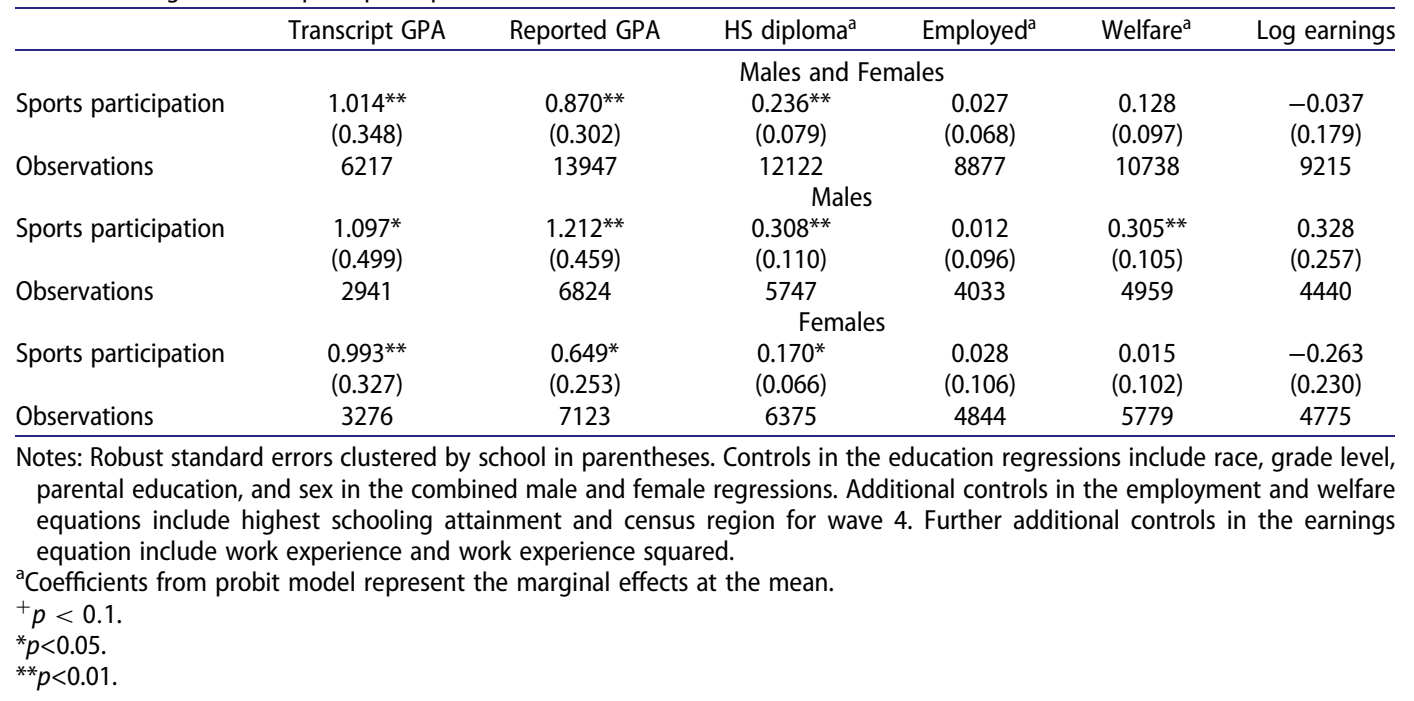


Table 9. Effect of sports participation on GPA using IV quantile regression.

\begin{tabular}{|c|c|c|c|c|c|}
\hline & 0.1 & 0.25 & 0.5 & 0.75 & 0.9 \\
\hline & \multicolumn{5}{|c|}{ Males and females } \\
\hline \multirow[t]{2}{*}{ Sports participation } & $1.488^{* *}$ & $1.104^{* *}$ & $0.802^{* *}$ & $0.763^{* *}$ & $0.702^{* *}$ \\
\hline & $(0.188)$ & $(0.193)$ & $(0.168)$ & $(0.150)$ & $(0.114)$ \\
\hline \multirow[t]{2}{*}{ Observations } & 6217 & 6217 & 6217 & 6217 & 6217 \\
\hline & & & Males & & \\
\hline \multirow[t]{2}{*}{ Sports participation } & $1.496^{* *}$ & $1.397^{* *}$ & $1.016^{* *}$ & $0.800^{* *}$ & $0.842^{* *}$ \\
\hline & $(0.453)$ & $(0.292)$ & $(0.294)$ & $(0.337)$ & $(0.326)$ \\
\hline \multirow[t]{2}{*}{ Observations } & 2941 & 2941 & 2941 & 2941 & 2941 \\
\hline & & & Females & & \\
\hline \multirow[t]{2}{*}{ Sports participation } & $1.656^{* *}$ & $0.995^{* *}$ & $0.624^{* *}$ & $0.833^{* *}$ & $0.552^{* *}$ \\
\hline & $(0.280)$ & $(0.233)$ & $(0.133)$ & $(0.122)$ & $(0.119)$ \\
\hline Observations & 3276 & 3276 & 3276 & 3276 & 3276 \\
\hline
\end{tabular}

Notes: Bootstrapped standard errors in parentheses. Controls include race, grade level, parental education, and sex in the combined male and female regressions.

${ }^{+} p<0.1$.

${ }^{*} p<0.05$.

${ }^{* *} p<0.01$

Table 10. Effect of sports participation on H.S. graduation by parental education using IV regression.

\begin{tabular}{|c|c|c|}
\hline & Low educated parents & High educated parents \\
\hline & & \\
\hline \multirow[t]{2}{*}{ Sports participation } & $0.217^{*}$ & $0.260^{* *}$ \\
\hline & $(0.100)$ & $(0.084)$ \\
\hline \multirow[t]{2}{*}{ Observations } & 4883 & 7239 \\
\hline & & \\
\hline \multirow[t]{2}{*}{ Sports participation } & $0.292^{*}$ & $0.328^{* *}$ \\
\hline & $(0.127)$ & $(0.110)$ \\
\hline \multirow[t]{2}{*}{ Observations } & 2259 & 3488 \\
\hline & & \\
\hline \multirow[t]{2}{*}{ Sports participation } & 0.138 & $0.197^{*}$ \\
\hline & $(0.112)$ & $(0.078)$ \\
\hline Observations & 2624 & 3751 \\
\hline
\end{tabular}

Notes: Robust standard errors clustered by school in parentheses. Controls include race, grade level, parental education, and sex in the combined male and female regressions.

${ }^{+} p<0.1$.

${ }^{*} p<0.05$.

${ }^{* *} p<0.01$.

Table 11. Effect of sports participation on earnings by quantile using IV regression.

\begin{tabular}{llllll}
\hline & 0.1 & 0.25 & 0.5 & 0.75 & 0.9 \\
\hline \multirow{2}{*}{ Sports participation } & & & Males and females & & \\
& -0.320 & -0.193 & 0.014 & 0.049 & $0.284^{+}$ \\
Observations & $(0.306)$ & $(0.125)$ & $(0.076)$ & $(0.073)$ & $(0.136)$ \\
& 9215 & 9215 & 9215 & 9215 & 9215 \\
Sports participation & & & Males & & 0.299 \\
Observations & -0.110 & 0.011 & 0.125 & $(0.156)$ & $(0.210)$ \\
Sports participation & $(0.481)$ & $(0.137)$ & $(0.123)$ & 4440 & 4440 \\
& 4440 & 4440 & 4440 & & 0.040 \\
Observations & -0.392 & -0.281 & -0.136 & -0.125 & $(0.100)$ \\
\hline
\end{tabular}

Notes: Bootstrapped standard errors in parentheses. Controls include race, grade level, parental education, highest level of schooling, experience, experience squared, region, and sex in the combined male and female regressions.

$+p<0.1$.

${ }^{*} p<0.05$.

${ }^{* *} p<0.01$. 
Table 6. Without controlling for endogeneity, the quantile results showed that low earners see the greatest gains from sports participation. The instrumental variable results, however, show mostly insignificant gains in earnings associated with sports participation. Not only are the results insignificant, but the gradient across quantiles is relatively flat. The differences in results could be explained by selection. Unobserved characteristics that lead to sports participation are important in the labor market, and these characteristics may be more important for the low earning segments of the population.

\section{Conclusion}

The distribution of benefits associated with sports participation provides new insights into the impact of sports on outcomes. These results aid both policy makers in understanding who benefits from sports participation and researchers in clarifying the avenues through which participation affects outcomes. The disparity between team sports and individual sports implies that there may be benefits to participating on a team and interacting with teammates that are not realized through individual sports participation. It suggests that policy makers should consider not just whether to create sports programs, but also think about which sports should be available to students.

The distributional analysis shows that sports participation has the largest impact on students' GPA at the bottom of the GPA distribution, thus helping struggling students earn higher grades. This may be the result of socializing with high achieving peers or driven by incentives to continue playing sports. Even if participating does not lead to direct human capital gains, sports opportunities may provide a carrot for some kids to stay in school and keep up their grades. Since low achieving students see greater performance gains, sports participation provides a way to level the playing field.

Finally, the fact that labor market effects disappear when accounting for endogeneity suggest that correlations between labor market outcomes and sports participation beyond academic improvements may be driven by selection. Thus, while sport participation may not lead to improved wages, it could be a good signal to employers of important unobserved worker characteristics.

\section{Notes}

1. Studies find that participants perform better in the classroom (Barron, Ewing, and Waddell 2000; Videon 2002) attain more schooling (Rehberg and Schafer 1968; Spreitzer and Pugh 1973; Long and Caudill 1991; Barron, Ewing, and Waddell 2000; Videon 2002; Stevenson 2010), and perform better in the marketplace (Long and Caudill 1991; Ewing 1998; Stevenson 2010)

2. Stevenson (2010) addresses this question for women by using Title IX implementation as an instrument for female athletic participation. She concludes that there is a causal effect of sports leading to increased college enrollment and labor force participation. Barron, Ewing, and Waddell (2000) use the Becker (1965) allocation of time model to infer that the effect of athletic participation on wages and educational attainment reflects differences in participants ability and value of leisure. However, they do not completely rule out the potential for athletic participation to enhance productivity. Other papers that address the causal relationship include the following: Eide and Ronan (2001) instrument for sports participation with height; Lechner (2009) uses a matching strategy; Lipscomb (2007) uses a fixed effects strategy with panel data; Pfeifer and Cornelissen (2001) instrument for sports participation in Germany with city size; Rooth (2011) conducts a field experiment in the market place; and Huang and Humphreys (2012) instrument for physical activity with the number of sports facilities in one's area.

3. Lechner and Downward (2013) use a matching strategy to analyze differential effects of sports participation on labor market outcomes in England across sport, gender, and age.

4. Coleman (1961) argues that athletic participation was a strong determinant of being in the leading crowd. Rehberg and Schafer (1968) corroborate this finding and argue that socializing with the leading crowd increases the educational expectations for those less disposed towards schooling.

5. The data does not distinguish whether the student is actually playing the sport in school or if they participate in a club outside of school. However, it is customary to play sports in school in the United States and those that play in a club outside of school will typically do so in addition to playing for the school.

6. The 'other' category is left out of the team and individual sport categories. However, results do not change significantly if this group is included in either category. Tennis doubles may be considered a team sport, but we can not differentiate between singles and doubles. If tennis is treated as a team sport, the results have the same pattern. 
7. This is consistent with the way GPA is typically calculated in US schools.

8. Wave 1 sample weights are used for the reported GPA and high school graduation regressions, wave 3 education sample weights are used in the transcript GPA regressions, and wave 4 sample weights are used for the labor market regressions. The weights try to account for sample attrition in later waves. The results do not differ substantially if the weights are not used.

9. Barron, Ewing, and Waddell (2000) also use a measure of school region, library books available to students, faculty student ratios, and height and health measures. These are not included as instruments in this paper because these measures are likely to affect outcome measures directly and thus violate the exclusion restriction. Pfeifer and Cornelissen (2001) differs slightly by employing city size in Germany where sports participation is based on city of residence instead of school. Other papers in the literature instrument with height (see Pfeifer and Cornelissen 2001; Eide and Ronan 2001), but given the relation found between height and health in recent literature (see Case and Paxson 2008a, 2008b; Case and Paxson 2010) it is unlikely that height satisfies the exclusion restriction.

10. Theory suggests that there could be benefits of large schools because they can provide more varied curriculum or there could be drawbacks due to limited sports participation and less personalization. Benefits of varied curriculum would bias the IV results downward. Limited sports participation is the effect that should drive the IV results. If less personalization affects outcomes negatively then this could create positive bias in the IV results.

11. See Levine (2010) for a review of small learning community programs. Overall, there are insignificant effects on academic performance. This is despite the fact that these programs are coupled with additional support beyond just decreasing school size that should lead to improvements in performance.

12. In the Durbin-Wu-Hausman test of endogeneity, the null that school sports is exogenous for the educational outcome specifications is rejected at the $5 \%$ level or less. While we fail to reject the null at the $5 \%$ level or less for work outcomes, the null can be rejected at the $10 \%$ level for the welfare specification. In the Hansen test of over-identifying restrictions, the null that the over-identifying restrictions are valid cannot be rejected at the $5 \%$ level for most outcomes. For the welfare and earnings specifications, the null cannot be rejected at the $1 \%$ level, but can be rejected at the $5 \%$ level.

\section{Acknowledgments}

This research uses data from Add Health, a program project directed by Kathleen Mullan Harris and designed by J. Richard Udry, Peter S. Bearman, and Kathleen Mullan Harris at the University of North Carolina at Chapel Hill, and funded by grant P01-HD31921 from the Eunice Kennedy Shriver National Institute of Child Health and Human Development, with cooperative funding from 23 other federal agencies and foundations. Special acknowledgment is due Ronald R. Rindfuss and Barbara Entwisle for assistance in the original design. Information on how to obtain the Add Health data files is available on the Add Health website (http://www.cpc.unc.edu/addhealth). No direct support was received from grant P01-HD31921 for this analysis.

\section{Disclosure statement}

No potential conflict of interest was reported by the author.

\section{References}

Angrist J. D., and V. Lavy. 1999. "Using Maimonides' Rule to Estimate the Effect of Class Size on Scholastic Achievement." The Quarterly Journal of Economics 114 (2): 533-575. doi:10.1162/003355399556061.

Barron J. M., B. T. Ewing, and G. R. Waddell. 2000. "The Effects of High School Athletic Participation on Education and Labor Market Outcomes." The Review of Economics and Statistics 82 (3): 409-421. doi:10.1162/003465300558902.

Becker G. S. 1965. "A Theory of the Allocation of Time." Economics Journal 75: 493-517. doi:10.2307/2228949.

Bound J., D. A. Jaeger, and R. M. Baker. 1995. "Problems with Instrumental Variables Estimation When the Correlation Between Instruments and the Endogenous Explanatory Variable is Weak." Journal of the American Statistical Association 90 (430): 443-450. doi:10.1080/01621459.1995.10476536.

Case A., and C. Paxson. 2008a. "Height, Health, and Cognitive Function at Older Ages." American Economic Review: Papers and Proceedings 98 (2): 463-467.

Case A., and C. Paxson. 2008b. "Stature and Status: Height, Ability, and Labor Market Outcomes." The Journal of Political Economy 116 (3): 499-532. doi:10.1086/589524.

Case A., and C. Paxson. 2010. "Causes and Consequences of Early-Life Health." Demography47-Supplement: S65-S85. doi:10.1353/dem.2010.0007.

Chernozhukov V., I. Fernandez-Val, and A. E. Kowalski. 2014. "Quantile Regression with Censoring and Endogeneity." Journal of Econometrics. doi:10.1016/j.jeconom.2014.06.017. 
Coleman J. S. 1961. "Athletics in High School." Annals of the American Academy of Political and Social Science 338: 33-43. doi:10.1177/000271626133800105.

Eide E. R., and N. Ronan. 2001. "Is Participation in High School Athletics an Investment or Consumption Good? Evidence from High School and Beyond." Economics of Education Review 20: 431-442. doi:10.1016/s0272-7757(00)00033-9.

Ewing B. T. 1998. "Athletes and Work." Economics Letters 59: 113-117. doi:10.1016/S0165-1765(98)00006-8.

Harris K. M. 2003. "The National Longitudinal Study of Adolescent Health (AddHealth), Waves I\&II, 1994-1996; Wave III, 2001-2002; Wave IV, 2007-2009 [machine-readable data file and documentation]." Chapel Hill, NC: Carolina Population Center, University of North Carolina at Chapel Hill.

Harris K. M., C. T. Halpern, E. Whitsel, J. Hussey, J. Tabor, P. Entzel, and J. R. Udry. 2009. “The National Longitudinal Study of Adolescent Health: Research Design." http://www.cpc.unc.edu/projects/addhealth/design.

Huang H., and B. R. Humphreys. 2012. "Sports Participation and Happiness: Evidence from U.S. Microdata." Journal of Economic Psychology 33: 776-793. doi:10.1016/j.joep.2012.02.007.

Koenker R., and K. F. Hallock. 2001. "Quantile Regression." Journal of Economic Perspectives 15 (4): 143-156. doi:10.1257/ jep.15.4.143.

Krueger A. B., and D. Whitmore. 2001. "The Effect of Attending a Small Class in the Early Grades on College Test-Taking and Middle School Test Results: Evidence from Project STAR." Economic Journal 111: 1-28. doi:10.1111/1468-0297. 00586.

Lechner M. 2009. "Long-Run Labour Market and Health Effects of Individual Sports Activities." Journal of Health Economics 28: 839-854. doi:10.1016/j.jhealeco.2009.05.003.

Lechner M., and P. Downward. 2013. "Heterogenous Sports Participation and Labour Market Outcomes in England." IZA Discussion Paper, (7690).

Levine T. H. 2010. "What Research Tells Us About the Impact and Challenges of Smaller Learning Communities." Peabody Journal of Education 85: 276-289. doi:10.1080/0161956x.2010.491431.

Lipscomb S. 2007. "Secondary School Extracurricular Involvement and Academic Achievement: A Fixed Effects Approach." Economics of Education Review 26: 463-472. doi:10.1016/j.econedurev.2006.02.006.

Long J. E., and S. B. Caudill. 1991. "The Impact of Participation in Intercollegiate Athletics on Income and Graduation." The Review of Economics and Statistics 73 (3): 525-531. doi:10.2307/2109580.

NFHS. 2014. "2013-14 High School Athletics Participation Survey." http://www.nfhs.org.

Pfeifer C., and T. Cornelissen. 2001. "The Impact of Participation in Sports on Educational Attainment - New Evidence from Germany." Economics of Education Review 29: 94-103. doi:10.1016/j.econedurev.2009.04.002.

Rehberg R. A., and W. E. Schafer. 1968. "Participation in Interscholastic Athletics and College Expectations." The American Journal of Sociology 73 (6): 732-740. doi:10.1086/224566.

Rooth D.-O. 2011. "Work Out or Out of Work - The Labor Market Return to Physical Fitness and Leisure Sports Activities." Labour Economics 18: 399-409. doi:10.1016/j.labeco.2010.11.006.

Rouse C. E., and L. Barrow. 2009. "School Vouchers and Student Achievement: Recent Evidence and Remaining Questions." Annual Review of Economics 1 (1): 17-42. doi:10.1146/annurev.economics.050708.143354.

Spreitzer E., and M. Pugh. 1973. "Interscholastic Athletics and Educational Expectations." Sociology of Education 46 (2): 171-182. doi:10.2307/2112095.

Staiger D., and J. H. Stock. 1997. "Instrumental Variables Regression with Weak Instruments." Econometrica 65 (3): $557-$ 586. doi:10.2307/2171753.

Stevenson B. 2010. "Beyond the Classroom: Using Title IX to Measure the Return to High School Sports." Review of Economics and Statistics 92 (2): 284-301. doi:10.1162/rest.2010.11623.

Stock J. H., and M. Yogo. 2005. "Testing for Weak Instruments in Linear IV Regression." In Identification and Inference for Econometric Models: Essays in Honor of Thomas J. Rothenberg, edited by D. W. K. Andrews and J. H. Stock, 80-108. New York: Cambridge University Press.

Videon T. M. 2002. "Who Plays and Who Benefits: Gender, Interscholastic Athletics, and Academic Outcomes." Sociological Perspectives 45 (4): 415-444. doi:10.1525/sop.2002.45.4.415. 